\title{
Prevalence of thyroid dysfunctions in a large, unselected population in Duhok city, Iraqi Kurdistan: A cross-sectional study
}

\author{
Burhan Abdullah Zaman, ${ }^{1}$ Suzan Omer Rasool, ${ }^{2}$ Saeed Mohammed Sabri, ${ }^{3}$ Ghazwan A. M. Raouf, ${ }^{1}$ \\ Amer A. Balatay, ${ }^{2}$ Mohammed Amin Abdulhamid, ${ }^{4}$ Darya Salih Hussein, ${ }^{4}$ Simona Khamo Odisho, ${ }^{1}$ \\ Sarah Talal George, ${ }^{5}$ Salar Mahmood Hassan, ${ }^{4}$ Ronahi Farhad Salman, ${ }^{4}$ Maryam Walantin Benyamin ${ }^{4}$ \\ ${ }^{1}$ Department of Pharmacology; ${ }^{2}$ Department of Clinical Pharmacy, College of Pharmacy, University of Duhok, Kurdistan \\ region; ${ }^{3}$ Medical Chemistry, College of Medicine, University of Duhok, Kurdistan Region; ${ }^{4}$ College of Pharmacy, \\ University of Duhok, Kurdistan Region; ${ }^{5}$ Bahdinan Health Centre, Duhok General Health Directorate, Duhok, \\ Kurdistan Region, Iraq
}

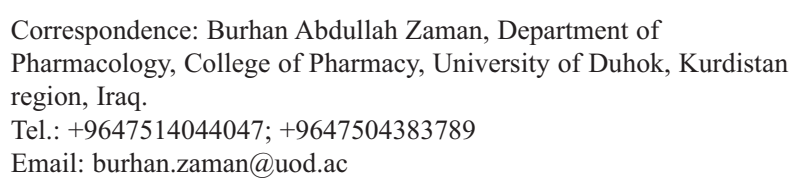

Key Words: TSH alteration; thyroid dysfunctions; Duhok City; Iraqi Kurdistan.

Acknowledgments: The authors of the study would like to present their deep thanks to Duhok Central Laboratory, Hivi Pediatric Teaching Hospital, and Amr Lab. for their kind cooperation and assistance. Also, we would like to present our sincere gratitude to $\mathrm{Mr}$. Deldar Morad Abdulah, for his precious time spending with us to fulfill statistical analysis.

Contributions: BAZ: Study concept and study design, data extraction, design of algorithm, and wrote methodology, statistical analysis, results, discussion and abstract; SOR: Study concept and study design, data extraction, wrote introduction and abstract, review and editing; SMS: Study concept, design of algorithm, review and editing; GAMR: Study concept, data collection, data entry, review and editing; AAB: Study concept, data verification, review and editing; SKO: Data entry, review and editing; STG: Data entry, review and editing; MAA: Coordinator of the team data collection and entry, data collection, and data entry; DSH: Participate in writing and data entry; SMH, RFS, MWB: Data collection and data entry.

Conflicts of interest: The authors declare no conflict of interest.

Ethics approval: The study was approved by the local research ethics committee of Duhok Directorate General of Health registered as the reference number of 15102019-7 in 15th October, 2019.

Informed Consent: The confidentiality of the personal information of the subjects was protected throughout the study steps.

Received for publication: 29 August 2021.

Revision received: 25 October 2021.

Accepted for publication: 21 November 2021.

${ }^{\circ}$ Copyright: the Author(s), 2021

Licensee PAGEPress, Italy

Journal of Biological Research 2021; 94:10067

doi:10.4081/jbr.2021.10067

This article is distributed under the terms of the Creative Commons Attribution Noncommercial License (by-nc 4.0) which permits any noncommercial use, distribution, and reproduction in any medium, provided the original author(s) and source are credited.

\begin{abstract}
This study aimed to determine the prevalence of ThyroidStimulating Hormone (TSH) alterations and different types of thyroid dysfunctions in both sexes with no age limitations from variety of sources in Duhok province. In this retrospective cross-sectional study, we screened 25040 suspicious cases of thyroid diseases in a year (2019), retrieving the data from the computers of three clinical laboratories of Duhok City. Following exclusion of 470 cases, 24568 cases were included to categorize the different types of thyroid dysfunctions. The prevalence of TSH alteration was $25.03 \%, 20.55 \%$ of them had a high concentration being statistically higher in females, while only $4.48 \%$ was low TSH with equal prevalence among both sexes. Out of 24568 patients, the prevalence of subclinical hypothyroidism was $94.85 \%$, followed by $2.20 \%, 1.20 \%, 0.78 \%, 0.67 \%$, and $0.31 \%$ for each of subclinical hyperthyroidism, primary hypothyroidism, central hyperthyroidism, central hypothyroidism, and primary hyperthyroidism respectively. In conclusion, the studied population had high prevalence of high TSH level (20.55\%), being more prevalent in female than in male. Our survey revealed that the distribution of thyroid disorders varied among different age groups with highest prevalence of subclinical hypothyroidism in all age groups $(94.85 \%)$. We also concluded that middle and advanced ages, and females were more susceptible to thyroid disorders.
\end{abstract}

\section{Introduction}

Thyroid hormones regulate most of the metabolic processes of the body. Therefore, alterations in their synthesis or function led to important health disturbances. ${ }^{1}$ Thyroid dysfunctions are among the leading endocrine disorders, around $30 \%$ to $40 \%$ of the patients seen in an endocrine department have thyroid disorders. ${ }^{2}$ About one-third of the world's population lives in areas deficient in iodine. Cross-sectional studies in Europe, USA and Japan have determined the prevalence of hyperthyroidism and hypothyroidism, and the frequency and distribution of different thyroid autoantibodies in these communities. ${ }^{3}$

Thyroid abnormalities affect a considerable proportion of the population. However, the prevalence and pattern of thyroid disorders depend on ethnic and geographical factors, especially iodine intake. ${ }^{4}$ Autoimmune thyroid diseases most commonly affect females, both genetic and environmental factors are involved in their pathogenesis. ${ }^{5}$ 
Based on laboratory results, the major disorders are hyperthyroidism and hypothyroidism with 1.6 billion people at risk in more than 110 countries around the world. ${ }^{6}$ Both disorders can be classified according to their origin as primary, if the condition is in the thyroid gland, or central, if the defect is in the hypophysis or in the hypothalamus. In addition, patients may suffer from subclinical hypo or hyperthyroidism, where there are no symptoms, but the concentration of thyroid-stimulating hormone (TSH; aka: thyrotropin) is altered. ${ }^{7}$

Morbidity associated with thyroid dysfunctions is well known with evident consequences in terms of altered serum cholesterol levels, increased risk of coronary artery disease and cardiovascular mortality. ${ }^{8}$

Based on the United Nations Children's Fund (UNICEF) global databases on iodized salt, on June 2019, the consumption of iodized salt among Iraqi citizens including Kurdistan region was $68.3 \% .{ }^{9}$

Kurdistan is considered among the endemic areas for goiter related to iodine deficiency, which is resulting from leaching of iodine from the soil by heavy rains due to its mountainous nature. ${ }^{10}$ The main consequences of long-term iodine deficiency in adults are a high prevalence of goiter, thyroid nodules, and hyperthyroidism. ${ }^{11}$

While there are no any large-scale prevalence studies regarding thyroid dysfunctions in Kurdistan region beside of other Iraqi provinces and because of the important impact of these diseases individually and on the society, therefore this article could be helpful to understanding the nature and main types of these complex problems via exploring the epidemiologic data surrounding thyroid dysfunctions by analyzing prevalence of their different types in different age groups and both sexes from variety of sources in Duhok province.

\section{Materials and Methods}

\section{Study design and population}

A retrospective cross-sectional study was conducted on patients which requested for thyroid function tests, including serum concentrations of TSH, Triiodothyronine (T3), Thyroxine (T4), and Thyroid Peroxidase (TPO) antibody at three different laboratories, Duhok Central Laboratory, Hivi Pediatric Teaching Hospital, and Amr Laboratory, in Duhok city, Kurdistan region of Iraq. The study was carried out by collecting the data of all patients clinically suspected of thyroid disorders who requested their tests from $1^{\text {st }}$ January to $31^{\text {st }}$ December, 2019.

\section{Sample size, data collection and data extraction}

A total of 25040 subjects of both sexes and different age groups, with no limitations, who attended the aforementioned laboratories requesting thyroid function tests were enrolled. Out of this number, 472 cases were excluded: 150 cases with only TPO antibody test and 322 with missed TSH results, that made the final number of 24568 participants in the current study. The secondary source-based laboratory records were used with patient identification data, age, sex, date of test and test results.

\section{Thyroid profile analysis}

Measurements of TSH, T3 and T4 hormones were performed using Cobas e 411 Immuno-analyzer (Roche Diagnostics $\mathrm{GmbH}$, Germany).

For the determination of TSH, an electrochemiluminescence immunoassay (ECLIA) for the in vitro quantitative determination in human serum has been used, with measuring range of 0.005-100 $\mu \mathrm{IU} / \mathrm{mL}$ and the functional sensitivity of $0.014 \mu \mathrm{IU} / \mathrm{mL}$. Values below the lower detection limit were reported as $<0.005 \mu \mathrm{IU} / \mathrm{mL}$, and Values above the measuring range as $>100 \mu \mathrm{IU} / \mathrm{mL} .^{12}$

For the determination of T3 and T4, an ECLIA for the in vitro quantitative determination in human serum has been used, with measuring range of $0.30-10 \mathrm{nmol} / \mathrm{L}$ and $5.4-320 \mathrm{nmol} / \mathrm{L}$, respectively.

Biological reference intervals (BRI) published in the Laboratory Medicine Practice Guidelines ${ }^{13}$ and the kit catalogue of Elecsys Cobas on $10^{\text {th }}$ October, 2010 provided by the Roche Diagnostics $\mathrm{GmbH}$ (see Table 1) has been used for classification of thyroid dysfunctions. In addition, an algorithm for the diagnostic interpretation of the thyroid values was used:

- Primary hypothyroidism: i) High TSH and low T4, with normal T3; ii) High TSH and low T4, with low T3; iii) High TSH (>19.9 $\mu \mathrm{IU} / \mathrm{mL})$ and no T4, with normal T3; iv) High TSH (>19.9 $\mu \mathrm{IU} / \mathrm{mL}$ ) and no T4, with no T3.

- Subclinical hypothyroidism: i) High TSH and normal T4, with normal T3; ii) High TSH and normal T4; iii) High TSH (from lower limit up to $19.9 \mu \mathrm{IU} / \mathrm{mL}$ ) and no T4, with normal T3; iv) High TSH (from lower limit up to $19.9 \mu \mathrm{IU} / \mathrm{mL}$ ) and no T4, with no T3.

- Primary hyperthyroidism: i) Low TSH and high T4, and no T3; ii) Low TSH and high T3, and no T4; iii) Low TSH and high $\mathrm{T} 3$ and $\mathrm{T} 4$.

- Subclinical hyperthyroidism: i) Low TSH and normal T3; ii) Low TSH and normal T4; iii) Low TSH and normal T3 and T4. - Central hypothyroidism: i) Low TSH and low T4, regardless of T3; ii) Normal TSH and low T4, regardless of T3.

Table 1. Reference intervals of indicators of thyroid dysfunctions.

\begin{tabular}{lcccccc}
$\begin{array}{l}\text { Reference Intervals } \\
\text { Children and Adolescence }\end{array}$ & Minimum & Maximum & Minimum & Maximum & Minimum & Maximum \\
1- $\leq 3$ Months & 0.72 & 11.00 & 69.6375 & 218.824 & 1.2289 & 4.2244 \\
$4-\leq 12$ Months & 0.73 & 8.35 & 72.9842 & 205.952 & 1.3211 & 4.0708 \\
\hline$>1-\leq 6$ Years & 0.70 & 5.97 & 76.5884 & 189.2184 & 1.4133 & 3.8097 \\
$>6-\leq 11$ Years & 0.60 & 4.84 & 77.1033 & 177.6336 & 1.4286 & 3.5485 \\
\hline$>11-\leq 20$ Years & 0.51 & 4.30 & 76.0735 & 169.9104 & 1.3979 & 3.3488 \\
Adults & Minimum & Maximum & Minimum & Maximum & Minimum & Maximum \\
$>20$ years & 0.27 & 4.20 & 65.6472 & 181.4952 & 1.2289 & 3.0723 \\
\hline
\end{tabular}


- Central hyperthyroidism: i) Normal TSH and high T4; ii) Normal TSH and high T3; iii) Normal TSH and high T3 and T4. $1,7,14,15$

\section{Control of bias}

The laboratories, that we collected data from them, perform the pre-analytical, analytical and post-analytical internal and external quality control. In the extraction of data, two authors of this study, $\mathrm{BAZ}$ and SOR, checked the collected data on excel sheets to prevent any repetition, missing data, and mismatched units to guarantee reproducibility of data. Also, a quality control of data was done in the database via a verification logic of ranges.

\section{Statistical methods}

The prevalence of thyroid dysfunctions was determined in number and percentage. The comparisons of prevalence of thyroid dysfunctions in subjects with different age groups and genders were identified in cross-tabulation. The correlation of thyroid indicators with age was examined in bivariate correlation. The prevalence of TSH level in subjects with different age groups and gender was examined in Pearson Chi-squared test. The significant level of difference was determined in a P-value of less than 0.05 . The statistical calculations were performed in JMP Pro 14.3.

\section{Ethical consideration}

The study was approved by the local research ethics committee of Duhok Directorate General of Health registered as the reference number of $15102019-7$ in $15^{\text {th }}$ October, 2019. The confidentiality of the personal information of the subjects was protected throughout the study steps.

\section{Results}

Of the 24568 persons who performed TSH test, 8063 were males $(32.82 \%)$ and 16505 were females $(67.18 \%)$. The vast majority of males and females were within normal level with $6451(80 \%)$ and $11967(72.5 \%)$ respectively. The lowest attendance (298 and 339 case) was recorded with age groups $(>3-\leq 12$ months) and $(\geq 70$ years) respectively; while most of the studied population were from age groups $>20-39$ years and 40-69 years $(18072,73.56 \%$ collectively). The highest prevalence of high and normal TSH was in age group 20-39 years with 2173 and 7012 cases respectively, while low TSH had the highest prevalence in age group 40-69 years with 451 cases (Table 2a and 3, and Figure 1a and 1b).

TSH decreased with increasing age in both genders with $r$-value of -0.00958 , but it was not statistically significant $(\mathrm{p}=0.1334)$. T3 and T4 decreased with increasing age with $r$-value of -0.10746 and -0.13277 respectively, and they were statistically significant ( $p$ $<0.0001$ in both hormones), as shown in Table $2 \mathrm{~b}$ and Figure 2 .

Primary hypothyroidism: It accounted for $1.20 \%$ of the studied population (294 cases), including males $(0.9 \%, 75)$ and females $(1.3 \%, 219)$. The highest prevalence among males and females was seen in age group 40-69 years (38, and 100 cases), followed by $>20$ 39 years (21, and 84 cases) respectively.

Subclinical hypothyroidism: It was the largest group of thyroid dysfunctions, which was reported in 23302 (94.85\%) cases; of that, 7672 (95.2\%) were males and 15630 (94.7\%) were females. The age group 40-69 years recorded the highest number of males with 2462 cases, while in females, the prevalence was higher in $>20-39$ years subjects with 6716 cases.

Table 2. (a) Distribution of the studied population according to age and sex group, (b) Correlation of indicators of thyroid dysfunction with age.

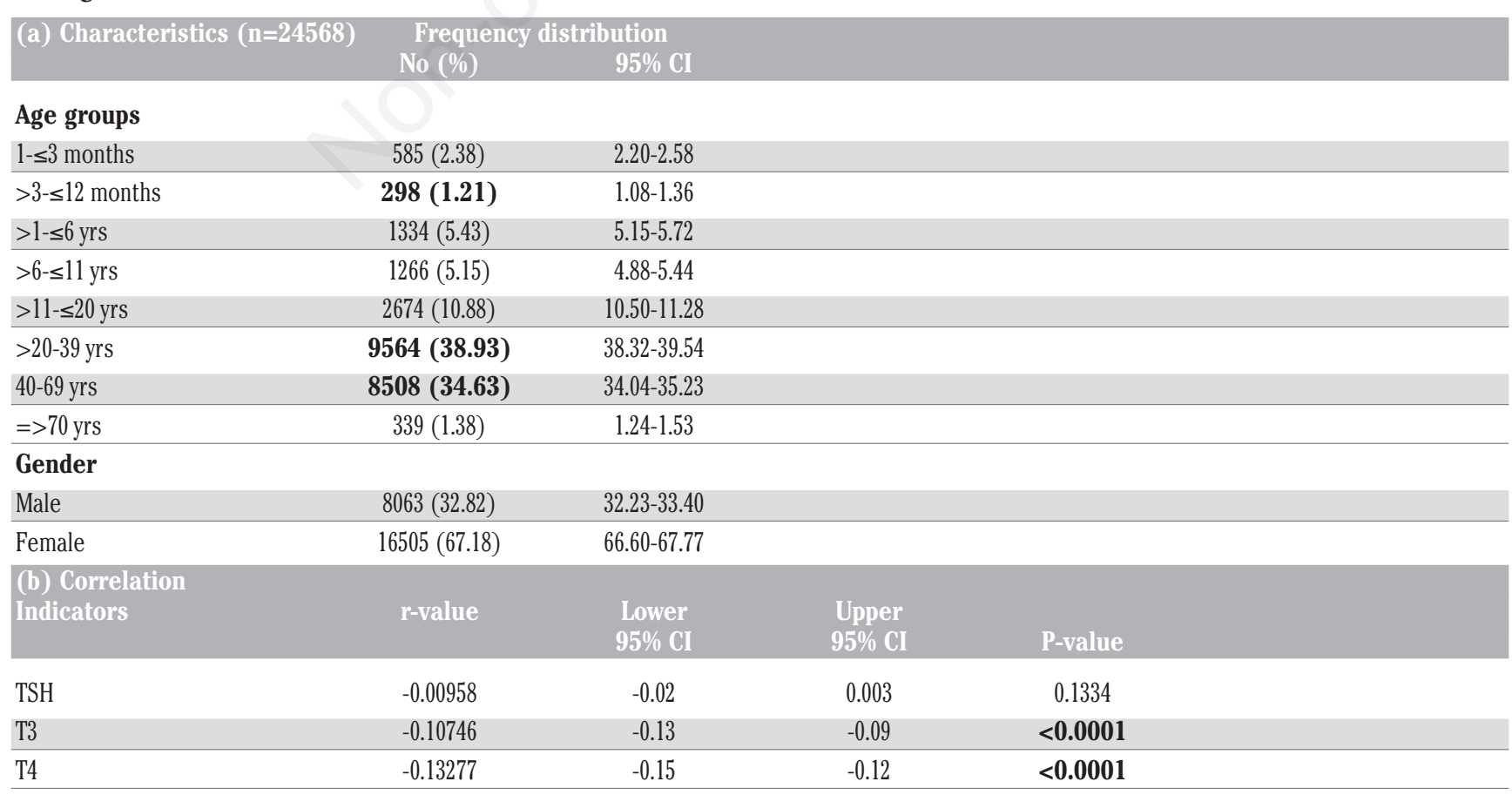


Table 3. Distribution of TSH level in subjects with different gender and age groups.

\begin{tabular}{|c|c|c|c|c|}
\hline Gender and age & $\begin{array}{l}\text { Low TSH } \\
\text { No }(\%)\end{array}$ & $\begin{array}{l}\text { TSH categories } \\
\text { Normal TSH } \\
\text { No (\%) }\end{array}$ & $\begin{array}{c}\text { High TSH } \\
\text { No }(\%)\end{array}$ & P-Value \\
\hline Total $(n=24568)$ & $1102(4.48)$ & $18418(74.97)$ & $5048(20.55)$ & \\
\hline \multicolumn{5}{|l|}{ Gender } \\
\hline Male & $360(4.5)$ & $6451(80.0)$ & $1252(15.5)$ & $<0.001$ \\
\hline Female & $742(4.5)$ & $11967(72.5)$ & $3796(23.0)$ & \\
\hline \multicolumn{5}{|l|}{ Age categories } \\
\hline $1-\leq 3$ months & $42(7.2)$ & $516(88.2)$ & $27(4.6)$ & \\
\hline$>3-\leq 12$ months & 35 (11.7) & $244(81.9)$ & $19(6.4)$ & \\
\hline$>1-\leq 6 \mathrm{yrs}$ & $56(4.2)$ & $1142(85.6)$ & $136(10.2)$ & \\
\hline$>6-\leq 11$ yrs & $34(2.7)$ & $1020(80.6)$ & $212(16.7)$ & $<0.001$ \\
\hline$>11-\leq 20 \mathrm{yrs}$ & $73(2.7)$ & 2019 (75.5) & $582(21.8)$ & \\
\hline $20-39$ yrs & $375(3.9)$ & $7012(73.3)$ & $2173(22.8)$ & \\
\hline $40-69$ yrs & $451(5.3)$ & $6226(73.2)$ & $1829(21.5)$ & \\
\hline$\geq 70 \mathrm{yrs}$ & $36(10.6)$ & $239(70.5)$ & $64(18.9)$ & 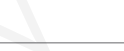 \\
\hline
\end{tabular}

Pearson chi-squared test was performed for statistical analyses.

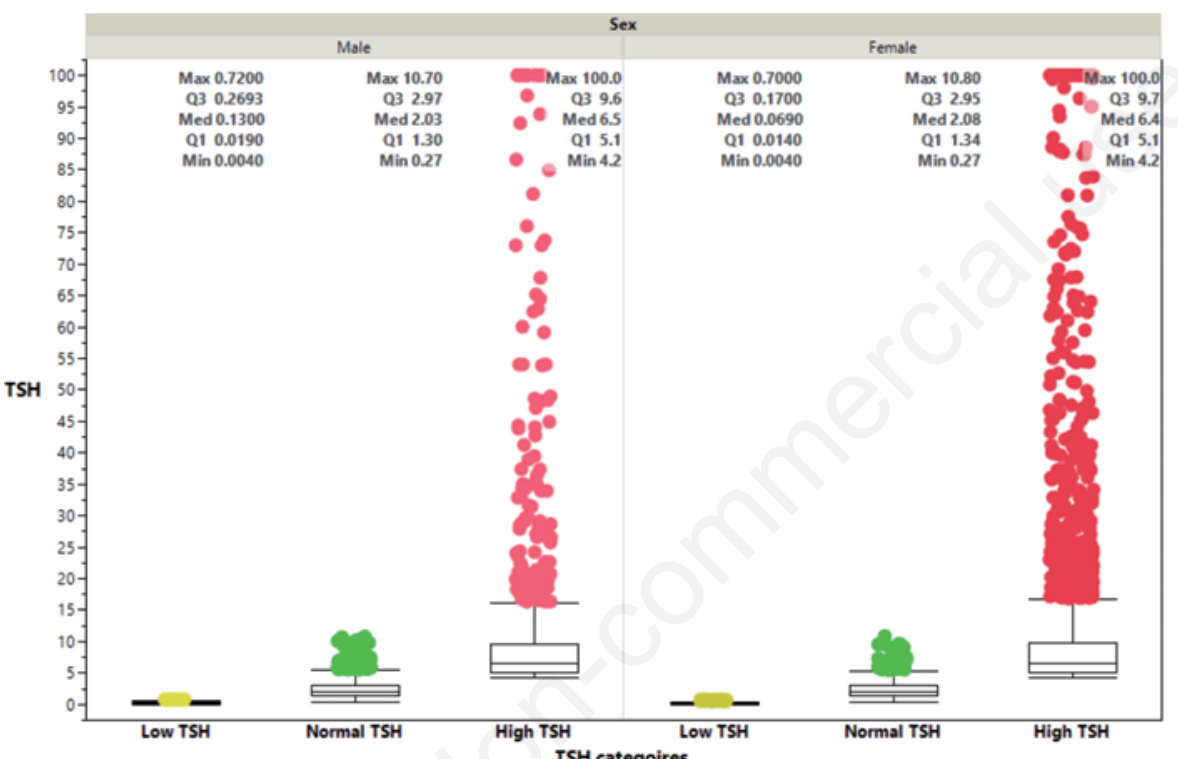

(a)

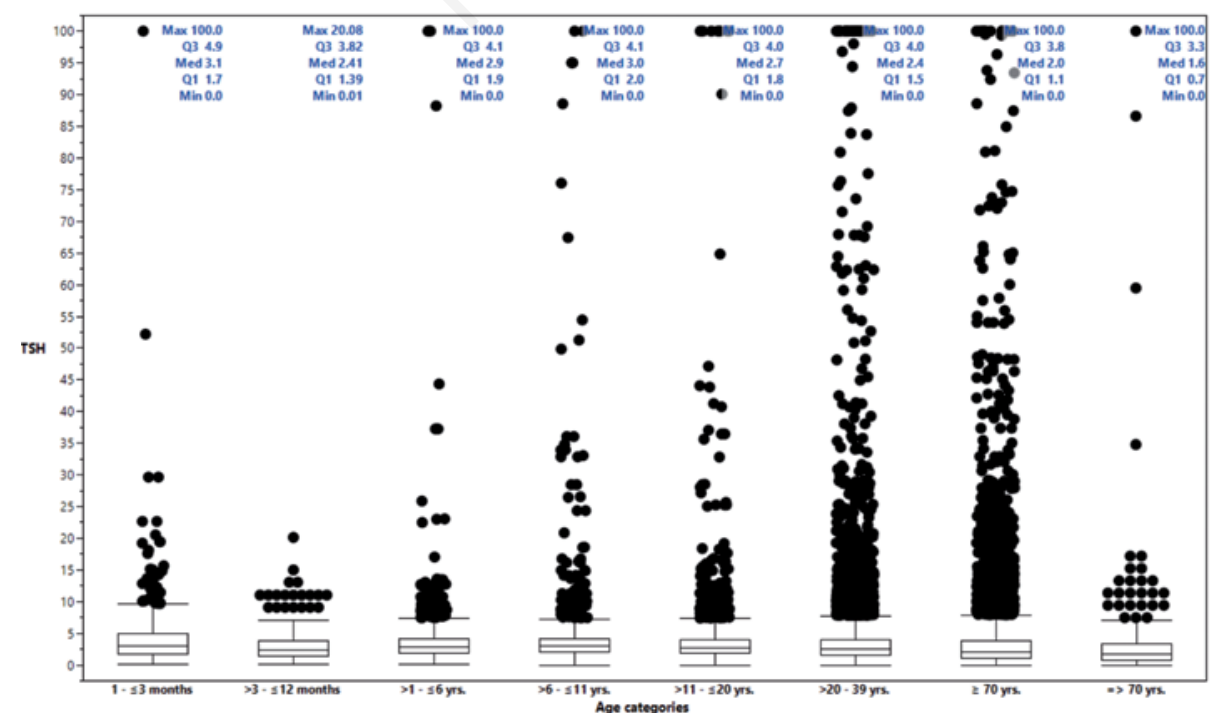

(b)

Figure 1. Categories of TSH: (a) between male and female subjects, (b) in subjects with different age groups. 
Primary hyperthyroidism: Only 76 (0.31\%) cases were reported to have primary hyperthyroidism, and considered as the smallest group of thyroid dysfunctions among others. There were 25 males and 51 females.

Subclinical hyperthyroidism: It was found in 540 patients (2.20\%), including 177 males $(2.2 \%)$ and 363 females $(2.2 \%)$. The highest prevalence among males and females was in age groups 4069 years (61, and 164 cases), followed by $>20-39$ years (50, and 128 cases) respectively.

Central hypothyroidism: It affected 165 individuals (0.67\%), with 65 males $(0.8 \%)$ and 100 females $(0.6 \%)$. The highest prevalence in males has been seen in age groups $>11-\leq 20$ years and 40-69 years with 15 cases each; also, in females, the highest prevalence was seen in age group $>20-39$ years with 33 patients.

Central hyperthyroidism: 191 cases $(0.78 \%)$ were reported including 49 males $(0.6 \%)$ and 142 females $(0.9 \%)$. The age group $>20$ - 39 years had the highest rate of prevalence with 18 males and 80 females.

In this study, all 24568 patients were classified with different thyroid dysfunctions based on the above-mentioned algorithm in the methodology section, as shown in Table 4 and 5, and Figure 3.

\section{Discussion}

This retrospective cross-sectional study was initiated to screen and categorize the various types of thyroid dysfunctions among highly suspicious cases who were referred to the laboratories by their physicians to confirm the diagnosis and determine the type of disease. To increase the plausibility and validity of our prevalence, all the subjects that have performed thyroid function tests during one year and in three major laboratories in Duhok city, enrolled in the study.

The prevalence of normal TSH levels was $74.97 \%$, and the prevalence of TSH alteration was $25.03 \%$, in which high TSH levels was $20.55 \%$, while only $4.48 \%$ was low TSH. These results are similar to those obtained in Colombia, one with $19 \%$ high TSH and $5.5 \%$ low TSH, ${ }^{1}$ and another with $18.5 \%$ high TSH and $2.1 \%$ low $\mathrm{TSH} .{ }^{16}$ Our findings demonstrate high prevalence of TSH level alterations compared to other studies performed in other countries, where it is about 5\% in England, ${ }^{3,17} \mathrm{USA}^{18}$ and Chile. ${ }^{19}$

The prevalence of low TSH among male and female subjects was equal ( $4.5 \%$ for each), but females have recorded high TSH levels more than males (23\% vs 15.5\%); and euthyroid males were $80 \%$ compared to $72.5 \%$ females. The lowest prevalence of low TSH levels was $2.7 \%$ among each of ( $>6-\leq 11$ years and $>11-\leq 20$ years) age groups, and the highest prevalence was among age groups of $(>3-$ $\leq 12$ months and $\geq 70$ years) with $11.7 \%$ and $10.6 \%$ respectively. The lowest and the highest rate for normal TSH levels were $70.5 \%$ and $85.6 \%$ in age groups ( $\geq 70$ years and $>1-\leq 6$ years) respectively; and high TSH levels with $4.6 \%$ was lowest in age group (1- $\leq 3$ months), and $22.8 \%$ among (20-39 years). The indicators of thyroid dysfunctions in this study were negatively correlated with age, but TSH correlation was not statistically significant $(p=0.1334)$ versus highly statistically significant correlation of $\mathrm{T} 3$ and $\mathrm{T} 4(\mathrm{p}<0.0001$, for

Table 4. Prevalence of thyroid dysfunctions in study subjects.

\begin{tabular}{lccccc} 
Thyyroid dysfunction categories & $\begin{array}{c}(\mathrm{n}=24568) \\
\text { Number }\end{array}$ & Percentage & $\begin{array}{c}95 \% \\
\text { CI }\end{array}$ & $\begin{array}{c}\text { Male } \\
\text { No (\%) }\end{array}$ & $\begin{array}{c}\text { Female } \\
\text { No (\%) }\end{array}$ \\
Primary Hypothyroidism & 294 & 1.20 & $1.07-1.34$ & $75(25.5)$ & $219(74.5)$ \\
Subclinical Hypothyroidism & 23302 & $\mathbf{9 4 . 8 5}$ & $94.56-95.12$ & $7672(32.9)$ & $15630(67.1)$ \\
\hline Primary Hyperthyroidism & 76 & $\mathbf{0 . 3 1}$ & $0.25-0.39$ & $25(32.9)$ & $51(67.1)$ \\
Subclinical Hyperthyroidism & 540 & 2.20 & $2.02-2.39$ & $177(32.7)$ & $363(67.3)$ \\
\hline Central Hypothyroidism & 165 & 0.67 & $0.58-0.78$ & $65(39.4)$ & $100(60.6)$ \\
Central Hyperthyroidism & 191 & 0.78 & $0.67-0.90$ & $49(25.7)$ & $142(74.3)$ \\
\hline
\end{tabular}

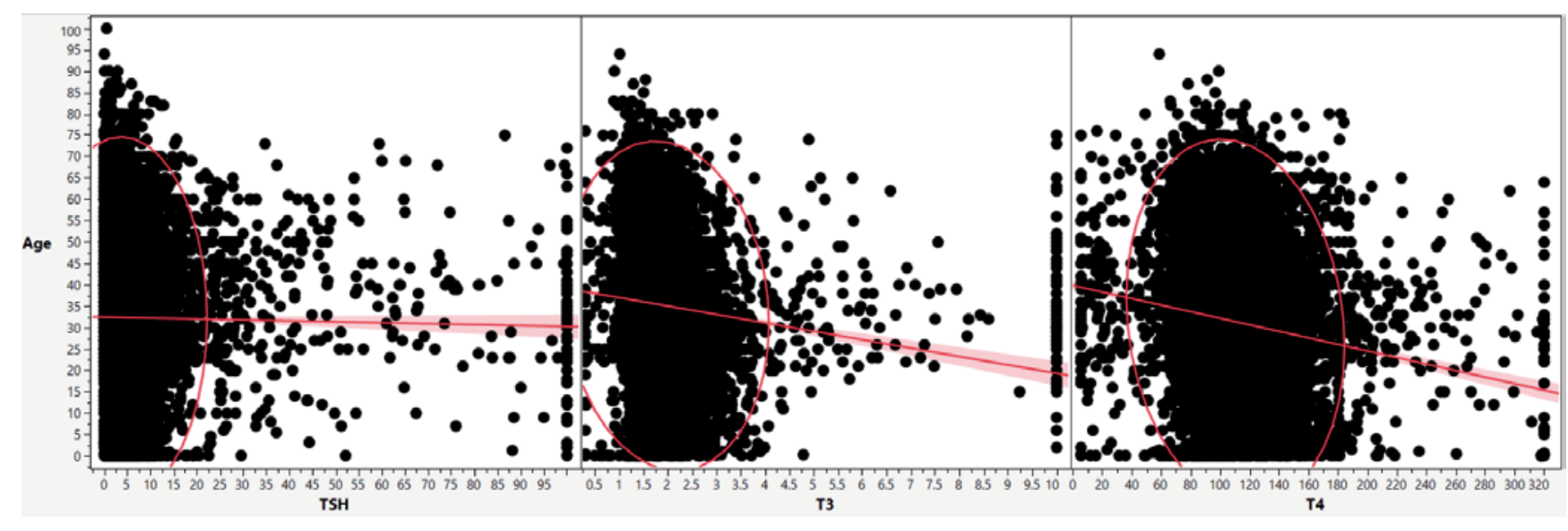

Figure 2. Scatter plot of correlation of indicators of thyroid dysfunctions with age. 
each). These data are in agreement with the studies done in other countries, for instance in England, ${ }^{3,17}$ Chile, ${ }^{19}$ and Colombia. ${ }^{1,20}$

Baloch et al. ${ }^{13}$ explained that the concentrations of TSH could be higher in children and adolescents due to progressive maturation of hypothalamus-hypophysis axis in children, where lowering the $\mathrm{TSH} / \mathrm{T} 4$ ratio from the middle of pregnancy to the end of puberty.

The low environmental iodine availability and increased iodine demand are the major causes of Iodine Deficiency Disorders (IDD). A high carbohydrate diet increases both T3 synthesis and iodine consumption, which finally results in the emergence of IDD. ${ }^{21}$ Fasting on other hand is correlated with low serum T3 and increased serum rT3, both restored to pre-fasting levels after refeeding with a mixed or mainly carbohydrate-rich diet. ${ }^{22}$ A study showed that a high glycemic index harms thyroid function, while a protein-rich and high saturated fatty acids diet has positive effects on thyroid functions. ${ }^{23}$

Iodine supplementation and iodized salt programs can prevent potential hazards of hypo- and hyper-thyroidism. ${ }^{10}$ The American Thyroid Association suggests supplements not more than $500 \mathrm{mcg}$ iodine per day. ${ }^{24}$

Nordic Nutrition Recommendation (NNR) diet is associated with maintaining normal iodine levels, whereas mild iodine deficiency is a fact while on the long-term use Paleo-Diet (PD). As a result, iodine supplementation should be addressed when on a PD. ${ }^{25}$
Based on the data revealed here, subclinical hypothyroidism is the most common disorder among our study subjects, and because our people mostly have a carbohydrate-rich diet, this will increase the chance of worsening the condition to become overt hypothyroidism. Therefore, we suggest to follow the NNR diet and decreasing the level of carbohydrates taken per day.

In regards to the thyroid dysfunction categories in our study, the highest prevalence $(94.85 \%$, with $95 \%$ CI of $94.56-95.12 \%$ ) was recorded for subclinical hypothyroidism, with distribution of $95.2 \%$ (7672) among males and 94.7\% (15630) in females; in a preliminary study performed during July 2014 to February 2015 in Duhok governorate, the prevalence of subclinical hypothyroidism in neonates was higher than our study $(7.9 \%$ vs $2.2 \%)$ respectively. ${ }^{26}$ The lowest prevalence $(0.31 \%$, with $95 \%$ CI of $0.25-0.39 \%)$ was registered for primary hyperthyroidism, with distribution in males and females of $0.3 \%(25)$ and $0.3 \%(51)$ respectively.

Hypothyroidism is 5 to 8 times more common in women than men due to mainly autoimmune thyroiditis besides iodine intake and environmental factors, ${ }^{27}$ and our results demonstrate that the females were the dominate gender in all types of thyroid dysfunctions in study area with approximately as twice as the prevalence for males (67.18\% vs $32.82 \%$, respectively), with exception of primary hypothyroidism and central hyperthyroidism which were almost three times than the males, and it is in concordance with Hasan et al.
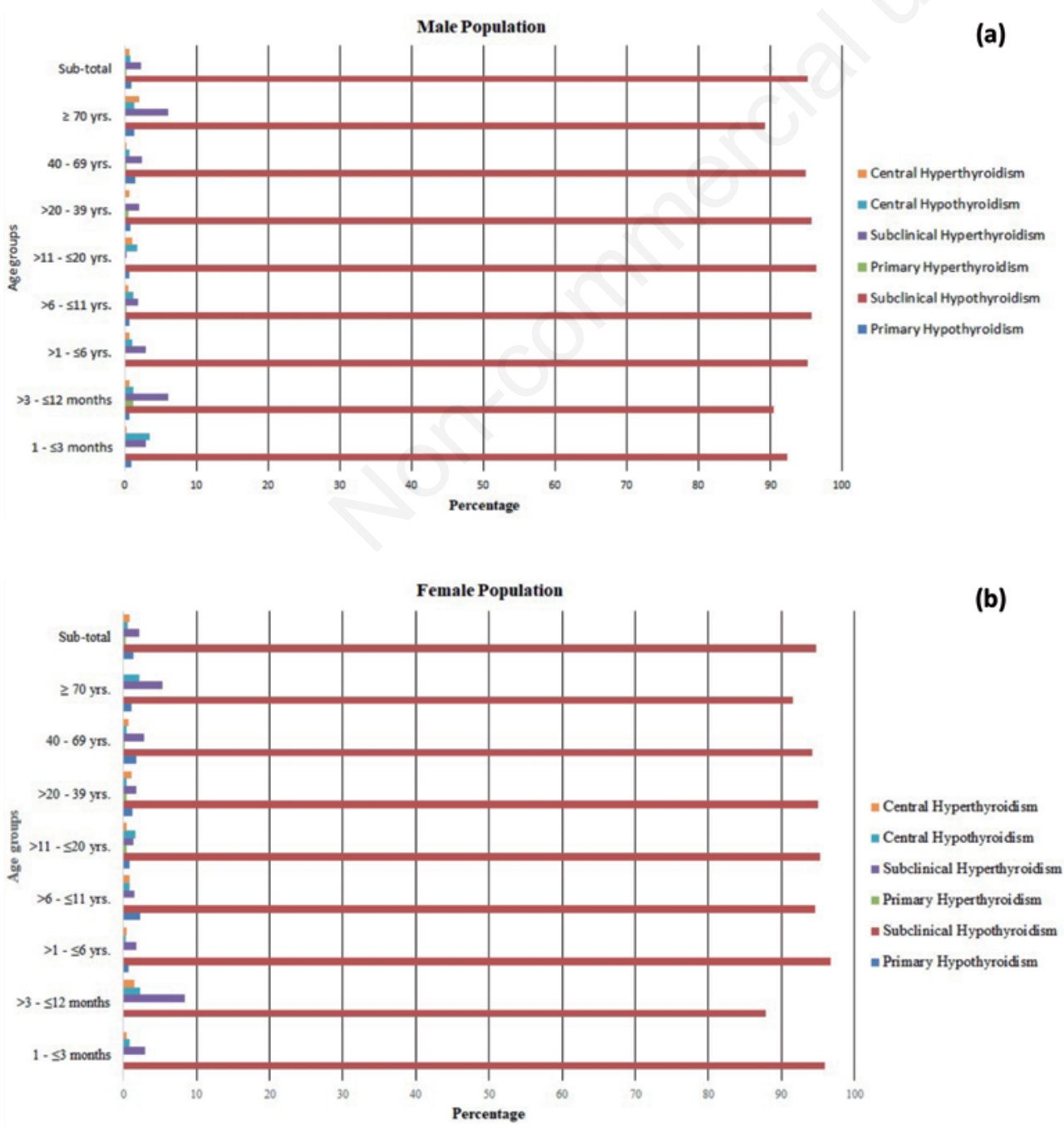

Figure 3. Distribution of prevalence of thyroid dysfunctions in subjects with different age groups: (a) Male population, (b) Female population. 
and Quasim et al. ${ }^{28,29}$ in Duhok governorate and with Amin et al., Hamasaeed et al., Al Barzanji et al. ${ }^{30-32}$ in Erbil governorate. Khattak et al. ${ }^{33}$ in their study in Iran from period of 1984 to 1990 with 25237 participants, stated that thyroid diseases prevail more among adults and women.

In a study conducted by Wsoo et al., ${ }^{34}$ from period of July 2015 to July 2016 in Ranya Town, Iraqi Kurdistan, 2013 individuals have been screened. They concluded that the highest prevalence was subclinical hyperthyroidism $(7.6 \%)$ followed by subclinical hypothyroidism $(6.01 \%)$, which is opposite to our results. While, in concordance with our findings, they revealed that the women had a greater susceptibility than men in each age group and in all types of disease.

A cross sectional study performed in Baghdad-Iraq, in a period of 6 months from July to December 2018 with participation of 1800 cases. ${ }^{35}$ They revealed that the prevalence of hypothyroidism (primary and subclinical) were higher than hyperthyroidism (primary and subclinical), and the highest prevalence was recorded with subclinical hypothyroidism (14.1\%) and the frequency of diseases was higher in adult ages and in females with approximately three times than males, which are totally in agreement with our results, but the prevalence percent of the types of the disease was close to each other in their study in opposite to ours with dominate distribution of cases in subclinical hypothyroidism.

Hashimoto's Thyroiditis (HT) and Graves' Disease (GD) are the commonest Autoimmune Thyroid Disease (AITD). It is now accepted that environmental factors, including dietary factors, genetic vulnerability, and immune diseases contribute to the AITD development. ${ }^{36}$ In the current study, because of missing data regarding TPO and TSH receptor antibodies, we were unable to diagnose and categorize HT and GD among our participants.

Besides routine treatments, patients might use nutritional interventions to alleviate hypothyroid symptoms. Given the importance of HT and GD in the development of hypo- and hyperthyroidism, respectively, possible interventions to decrease serum TPO titers and thyroid-stimulating receptor antibodies are a popular inquiry. The most common interventions include food supplements with micro-nutrients (such as iodine, selenium, iron, zinc, and vitamin D), and confined taking certain foods. ${ }^{23,24,36}$ Other environmental factors, for instance, smoking, alcohol consumption, stress, infections, and medications like estrogens, could also have an impact on the thyroid dysfunction incidence. ${ }^{37}$ Physicians are better to consider these risk factors while dealing with these patients accordingly.

The majority of thyroid dysfunctions are frequently screened in adults, 30 to 50 years old. ${ }^{28,29,32,34,38}$ Also, our results demonstrate that the prevalence of all types were higher in age groups $>20-39$ years and 40-69 years, and the highest prevalence $(42.85 \%)$ in females were among age groups $>20-39$ years, while age 40-69 years was screened as the highest prevalence $(32.16 \%)$ among male individuals. Vadiveloo et al. ${ }^{39}$ stated that incidence rates of thyroid diseases increased with advanced patients ages. In agreement with a prevalence study done in Egypt by Rashad and Samir, ${ }^{40}$ in our study the prevalence of hyperthyroidism $(3.28 \%)$ was significantly less than hypothyroidism (96.72\%), while the opposite was established in a study in Erbil city ${ }^{31}$ and in the Ranya town survey. ${ }^{34}$

Soy products and cruciferous vegetables are the most popular

Table 5. Prevalence of thyroid dysfunctions in male and female subjects with different age groups.

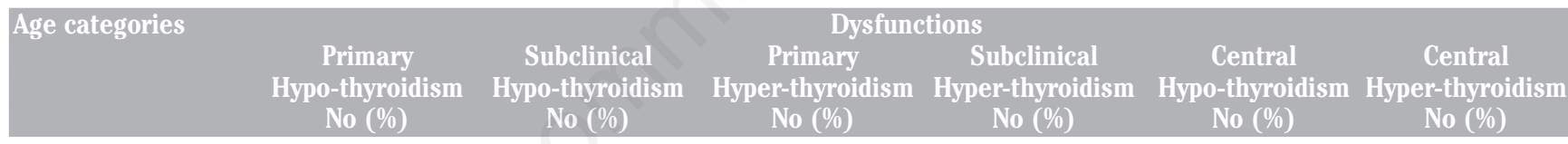

\section{Male}

\begin{tabular}{|c|c|c|c|c|c|c|}
\hline $1-\leq 3$ months & $3(0.9)$ & 317 (92.4) & $0(0.0)$ & $10(2.9)$ & $12(3.5)$ & $1(0.3)$ \\
\hline$>3-\leq 12$ months & $1(0.6)$ & $151(90.4)$ & $2(1.2)$ & $10(6.0)$ & $2(1.2)$ & $1(0.6)$ \\
\hline$>1-\leq 6$ yrs & $1(0.1)$ & 718 (95.2) & $0(0.0)$ & $22(2.9)$ & $8(1.1)$ & $5(0.7)$ \\
\hline$>6-\leq 11 \mathrm{yrs}$ & $4(0.6)$ & $634(95.8)$ & $1(0.2)$ & $12(1.8)$ & $8(1.2)$ & $3(0.5)$ \\
\hline$>11-\leq 20 \mathrm{yrs}$ & $5(0.6)$ & $874(96.4)$ & $1(0.1)$ & $3(0.3)$ & $15(1.7)$ & $9(1.0)$ \\
\hline$>20-39$ yrs & $21(0.8)$ & $2382(95.8)$ & $13(0.5)$ & $50(2.0)$ & $3(0.1)$ & $18(0.7)$ \\
\hline 40-69 yrs & $38(1.5)$ & $2462(94.9)$ & $8(0.3)$ & $61(2.4)$ & $15(0.6)$ & $9(0.3)$ \\
\hline$\geq 70 \mathrm{yrs}$ & $2(1.3)$ & $134(89.3)$ & $0(0.0)$ & $9(6.0)$ & $2(1.3)$ & $3(2.0)$ \\
\hline Sub-total & $75(0.9)$ & 7672 (95.2) & $25(0.3)$ & $177(2.2)$ & $65(0.8)$ & $49(0.6)$ \\
\hline \multicolumn{7}{|l|}{ Female } \\
\hline $1-\leq 3$ months & $0(0.0)$ & $232(95.9)$ & $0(0.0)$ & $7(2.9)$ & $2(0.8)$ & $1(0.4)$ \\
\hline$>3-\leq 12$ months & $0(0.0)$ & $115(87.8)$ & $0(0.0)$ & $11(8.4)$ & $3(2.3)$ & $2(1.5)$ \\
\hline$>1-\leq 6$ yrs & $4(0.7)$ & $561(96.7)$ & $0(0.0)$ & $10(1.7)$ & $2(0.3)$ & $3(0.5)$ \\
\hline$>6-\leq 11 \mathrm{yrs}$ & $14(2.3)$ & $574(94.6)$ & $0(0.0)$ & $9(1.5)$ & $5(0.8)$ & $5(0.8)$ \\
\hline$>11-\leq 20 \mathrm{yrs}$ & $15(0.8)$ & 1684 (95.3) & $7(0.4)$ & $24(1.4)$ & $28(1.6)$ & $9(0.5)$ \\
\hline$>20-39$ yrs & $84(1.2)$ & $6716(95.0)$ & $32(0.5)$ & $128(1.8)$ & $33(0.5)$ & $80(1.1)$ \\
\hline $40-69$ yrs & $100(1.7)$ & $5573(94.2)$ & $12(0.2)$ & $164(2.8)$ & $23(0.4)$ & $42(0.7)$ \\
\hline$\geq 70 \mathrm{yrs}$ & $2(1.1)$ & $175(91.5)$ & $0(0.0)$ & $10(5.3)$ & $4(2.1)$ & $0(0.0)$ \\
\hline Sub-total & 219 (1.3) & 15630 (94.7) & $51(0.3)$ & 363 (2.2) & $100(0.6)$ & $142(0.9)$ \\
\hline Total & 294 (1.2) & 23302 (94.85) & $76(0.31)$ & $540(2.20)$ & $165(0.67)$ & $191(0.78)$ \\
\hline
\end{tabular}


examples of goitrogenic substances well known so far. ${ }^{24}$ There were concerns that isolated isoflavones besides other soy products and supplements might be a significant issue for subclinical or overt hypothyroidism patients, mainly during pregnancy, as they could pose harm to thyroid function. While a meta-analysis on 2018-2019, found no effects of these products on thyroid functions and they may cause a moderate rise in TSH levels with an unclear significance clinically. ${ }^{41}$

In a study done on long-term use of pure genistein aglycone, an isoflavone, at a dose of $54 \mathrm{mg}$ per day, found no significant effects on subclinical and clinical hypothyroidism, while they suggest more human prospective studies to uncover all the potential issues concerning this product. ${ }^{42}$ Considering that thyroid diseases are gender and age-related, hence women (especially during childbearing age) and infants deserve special observation to evaluate the safety profile of isoflavones, including genistein on thyroid hormones and function. ${ }^{43}$

Based on an experimental study, the myoinositol combined with seleno-L-methionine can protect mice from damages induced by exposure of the thyroid gland to cadmium. It is noteworthy to say that the effect of these nutraceuticals was higher significantly than that of resveratrol. ${ }^{43}$

There is significant evidence that a robust thyroid-gut axis occurs, and dysbiosis is a prevalent finding in thyroid diseases. A healthy intestinal microbiota has positive effects on the immune system and thyroid function. It is well-known that thyroid disorders (GD and HT) and bowel diseases (celiac disease and non-celiac wheat sensitivity) prevalently coexist. Also, the deficiency of the most important micronutrients in AITDs, leading to thyroid malfunctioning. The probiotics were revealed to have a beneficial influence on thyroid disorders, by increasing the serum levels of these trace elements and are now considered as a promising adjuvant treatment for thyroid disorders. ${ }^{44}$

We recommend the future well-designed and well-powered animal and human studies to emphasize the significance of the effects of various dietary patterns and nutraceuticals on thyroid health, thyroid-gut axis and to explore the intervention possibilities.

\section{Strength and Limitations}

The strength of our study was the unselected large number of participants from broad age range, 1 month to $>70$ years old, and the high data rate, especially in the age group $20-69$ years; In those less than 1 year and over 70 years old, the attendance rate was lower (4.97\% collectively), which might explain the lower prevalence of all types of thyroid disorders in these groups. Also, the results might be influenced by the treatment options and diagnostic criteria as one of the major criticisms for retrospective studies, therefore we recommend a large prospective screening study to minimize the chance of any possible mistakes and bias.

\section{Conclusions}

In conclusion, the studied population had high prevalence of high TSH level $(20.55 \%)$, being more prevalent in female than in male. The alteration prevalence of indicators of thyroid dysfunctions showed a negative statistical correlation with age group and sex.

Our survey in Duhok City revealed that the distribution of thyroid disorders was varying among different age groups with highest prevalence of subclinical hypothyroidism in all age groups $(94.85 \%)$. Also, we concluded that middle and advanced ages, and females were more susceptible to thyroid disorders.

\section{References}

1. Carmona C, Bedoya P, Acevedo J, Arias J. Prevalence of thyroid disorders in an institution providing health services in MedellinColombia. Transl Biomed 2018;9:149.

2. Garmendia Madariaga A, Santos Palacios S, Guillén-Grima F, Galofré JC. The incidence and prevalence of thyroid dysfunction in Europe: a meta-analysis. J Clinical Endocrinol Metab 2014;99:923-31.

3. Vanderpump MP. The epidemiology of thyroid disease. Br Med Bull 2011;99:39-51.

4. Bjoro T, Holmen J, Krüger O, et al. Prevalence of thyroid disease, thyroid dysfunction and thyroid peroxidase antibodies in a large, unselected population. The Health Study of NordTrondelag (HUNT). Eur J Endocrinol 2000;143:639-47.

5. Strieder TG, Prummel MF, Tijssen JG, et al. Risk factors for and prevalence of thyroid disorders in a cross $\square$ sectional study among healthy female relatives of patients with autoimmune thyroid disease. Clin Endocrinol 2003;59:396-401.

6. Yadav NK, Thanpari C, Shrewastwa MK, et al. Socio demographic wise risk assessment of thyroid function abnormalities in far western region of Nepal: A hospital based descriptive study. Asian Pacific J Trop Dis 2013;3:150-4.

7. Hernandez AG. Principios de bioquímica clínica y patología molecular. Barcelona, Spain Elsevier; 2019.

8. Cappola AR, Fried LP, Arnold AM, et al. Thyroid status, cardiovascular risk, and mortality in older adults. JAMA 2006;295:1033-41.

9. United Nations Children's Fund. Consumption of iodized salt (\% of households) - Iraq The World Bank Website 2019. Available from: https://data.worldbank.org/indicator/SN.ITK. SALT.ZS end $=2018 \&$ locations $=I Q \&$ start $=2018 \&$ view $=$ map

10. Jawzali JI. Regional Differences of Drinking Water Iodine and Its Association with Thyroid Disorder and Serum Iodine. Med J Babylon 2017;14:198-208.

11. Khattak RM, Ittermann T, Nauck M, et al. Monitoring the prevalence of thyroid disorders in the adult population of Northeast Germany. Population Health Metrics 2016;14:1-11.

12. Nicoloff JT, Spencer CA. The use and misuse of the sensitive thyrotropin assays. J Clin Endocrinol Metab 1990;71:553-8.

13. Baloch Z, Carayon P, Conte-Devolx B, et al. Laboratory medicine practice guidelines. Laboratory support for the diagnosis and monitoring of thyroid disease. Thyroid 2003;13:3-126.

14. Burtis CA, Bruns DE. Tietz fundamentals of clinical chemistry and molecular diagnostics. e-book. Elsevier Health Sciences; 2014.

15. Baumgartner C, Da Costa BR, Collet T-H, Feller M, Floriani C, Bauer DC, et al. Thyroid function within the normal range, subclinical hypothyroidism, and the risk of atrial fibrillation. Circulation 2017;136:2100-16.

16. Londoño ÁL, Gallego ML, Bayona A, Landázuri P. Prevalencia de hipotiroidismo y relación con niveles elevados de anticuerpos antiperoxidasa y yoduria en población de 35 y más años en Armenia. 2009-2010. Revista de Salud Pública 2011;13:998-1009.

17. Tunbridge W, Evered D, Hall R, et al. The spectrum of thyroid disease in a community: the Whickham survey. Clin Endocrinol 1977;7:481-93.

18. Hollowell JG, Staehling NW, Flanders WD, et al. Serum TSH, T4, and thyroid antibodies in the United States population (1988 to 1994): National Health and Nutrition Examination Survey (NHANES III). J Clin Endocrinol Metab 2002;87:489-99. 
19. Fardella C, Poggi H, Gloger S, et al. Alta prevalencia de enfermedad tiroidea subclínica en sujetos que concurren a control de salud. Revista médica de Chile 2001;129:155-60.

20. Builes CA, Rosero Ó, García J. TSH levels in the evaluation of thryroid disfunction in a population group in Bogota. Acta Médica Colombiana 2006;31:66-70.

21. Kopp W. Nutrition, evolution and thyroid hormone levels-a link to iodine deficiency disorders? Medical Hypotheses 2004; 62:871-5.

22. Azizi F. Islamic fasting and thyroid hormones. Intern J Endocrinol Metab 2015; 13:e29248.

23. Dubravka B, Ivana G, Nikolina P, et al. The effect of food groups and nutrients on thyroid hormone levels in healthy individuals. Nutrition 2021:111394.

24. Bashar MA, Begam N. Role of dietary factors in thyroid disorders: Current evidences and way forwards. Thyroid Research Practice 2020;17:104.

25. Manousou S, Stål M, Larsson C, et al. A Paleolithic-type diet results in iodine deficiency: a 2-year randomized trial in postmenopausal obese women. Eur J Clinical Nutrition 2018; 72:124-9.

26. Al-Timimi DJ, Mustafa AH. Neonatal screening for congenital hypothyroidism in Duhok Governorate (Iraq); A preliminary study. Duhok Medical J 2019;13:20-30.

27. Visser WE, Visser TJ, Peeters RP. Thyroid disorders in older adults. Endocrinol Metab Clin 2013;42:287-303.

28. Hasan RI, Raziq AH. Studying the frequency of autoimmune thyroid diseases in Duhok Province. Sci J Univ Zakho 2019;7:45-9.

29. Qasim BA, Mohammed AA, Ahmed MJ. Lipid profile IN subclinical hypothyroidism: A two centers experience. Duhok Med J 2019;13:56-65.

30. Amin ZA, Tawfeeq RD, Kamal SI. The frequency of autoimmune thyroid disorders in patients with thyroid dysfunction in Erbil city. Zanco J Med Sci (Zanco J Med Sci) 2018;22:372-6.

31. Hamasaeed PA, Hussain SK, Ashraf SM. Evaluation of Thyroid stimulating hormone and thyroid hormone concentrations in females with hypothyroidism and hyperthyroidism. Rafidain J Sci 2019;28:1-7.

32. Al Barzanji BAM, Mustafa IH, Aziz KF. Socio-demographic and clinical characteristics of patients with thyroid disorders in Erbil Governorate/Iraq. Diyala J Med 2019;17:28-35.

33. Khattak KN, Shahmim A, Alam KM, et al. Distribution of thyroid patients between age groups, sex and seasons in the thyroid patients referred to irnum peshawar. J Med Sci 2001;1:400-3.

34. Wsoo MA, Rasul KH. Epidemicity of thyroid gland disorders among Ranya Town dwellers: A hospital-based survey. Zanco J Pure Appl Sci 2017;29:1-9.

35. Tahir NT, Najim HD, Nsaif AS. Prevalence of overt and subclinical thyroid dysfunction among Iraqi population in Baghdad city. Iraqi J Comm Med 2020;33:20.

36. Rayman MP. Multiple nutritional factors and thyroid disease, with particular reference to autoimmune thyroid disease. Proceed Nutrition Soc 2019;78:34-44.

37. Huang Y, Cai L, Zheng Y, et al. Association between lifestyle and thyroid dysfunction: A cross-sectional epidemiologic study in the She ethnic minority group of Fujian Province in China. BMC Endocr Disord 2019;19:1-9.

38. Al-Hindawi S, Al-Ghurabi B, andLuaibi N. The role of hla-drb1 allele in hypothyroid patients with and without periodontitis. Pak J Biotechnol 2017;14:629-34.

39. Vadiveloo T, Donnan PT, Murphy MJ, Leese GP. Age-and gender-specific TSH reference intervals in people with no obvious thyroid disease in Tayside, Scotland: the Thyroid Epidemiology, Audit, and Research Study (TEARS). J Clin Endocrinol Metab 2013;98:1147-53.

40. Rashad NM, Samir GM. Prevalence, risks, and comorbidity of thyroid dysfunction: a cross-sectional epidemiological study. Egyptian J Int Med 2019;31:635-41.

41. Otun J, Sahebkar A, Östlundh L, et al. Systematic review and meta-analysis on the effect of soy on thyroid function. Scientific Reports 2019;9:1-9.

42. Bitto A, Polito F, Atteritano M, et al. Genistein aglycone does not affect thyroid function: results from a three-year, randomized, double-blind, placebo-controlled trial. J Clin Endocrinol Metab 2010;95:3067-72.

43. Marini H, Polito F, Adamo EB, et al. Update on genistein and thyroid: an overall message of safety. Frontiers Endocrinol 2012;3:94.

44. Knezevic J, Starchl C, Tmava Berisha A, Amrein K. ThyroidGut-Axis: how does the microbiota influence thyroid function? Nutrients 2020;12:1769. 